SHORT REPORT

\title{
Lack of chromosomal imbalances in adamantinomatous and papillary craniopharyngiomas
}

\author{
C H Rickert, W Paulus
}

J Neurol Neurosurg Psychiatry 2003;74:260-261

Craniopharyngiomas are among the most common paediatric tumours and are thought to arise from embryonic remnants of Rathke's pouch. The molecular mechanisms involved in their formation remain elusive and little is known about chromosomal imbalances that could suggest the locations of tumour suppressor or proto-oncogenes involved in the pathogenesis. The paucity of published data on the molecular basis of such tumours prompted this investigation of 20 adamantinomatous and nine papillary craniopharyngiomas for genetic abnormalities by comparative genomic hybridisation (CGH). CGH revealed no DNA copy number changes in any of the 29 primary craniopharyngiomas, regardless of their histological subtype. These data suggest that chromosomal imbalances are a rare event in both adamantinomatous and papillary craniopharyngiomas.

C raniopharyngiomas are benign epithelial, slow growing tumours of the sellar region thought to arise from embryonic remnants of Rathke's pouch. ${ }^{1}$ They occur as either an adamantinomatous or a papillary subtype, corresponding histologically to WHO grade I, and they are among the most common childhood brain tumours. ${ }^{1}$ It is not known whether there is a genetic susceptibility to these tumours, but-as some craniopharyngiomas have occurred within families or among siblings - there are clues that genetic events may be involved in the pathogenesis. ${ }^{2}{ }^{3}$ However, as no investigations of genetic aberrations in biopsy tissue from craniopharyngiomas have so far been carried out, little is known about any possible chromosomal imbalances that could suggest the locations of tumour suppressor or protooncogenes. The paucity of data on the molecular basis of craniopharyngiomas prompted us to investigate 29 primary craniopharyngiomas by comparative genomic hybridisation $(\mathrm{CGH})$.

\section{METHODS}

\section{Patients and tumours}

Twenty nine formalin fixed and paraffin wax embedded biopsy specimens of primary craniopharyngiomas ( 13 male patients, 16 female; mean age 39.8 years, range 2 to 77 years) were investigated by CGH. These consisted of 20 adamantinomatous craniopharyngiomas (from 10 male and 10 female patients; mean age 33.6 years, range 2 to 77 years) and nine papillary craniopharyngiomas (from three male and six female patients; mean age 53.7 years, range 34 to 75 years). Only tumour portions that had been shown histologically to contain more than $80 \%$ tumour cells were included. Where necessary, dissection and trimming of the tissue blocks was undertaken in order to optimise tumour tissue retrieval.

\section{CGH analysis}

DNA was isolated by phenol-chloroform extraction according to standard protocols. CGH analysis was undertaken as described previously. ${ }^{4}$ Briefly, tumour DNA was labelled with biotin-16-dUTP (Boehringer Mannheim, Mannheim, Germany) and reference DNA from a healthy male donor with digoxigenin-1 1-dUTP (Boehringer Mannheim) in a standard nick translation reaction. The DNAse concentration in the labelling reaction was adjusted in order to reveal an average fragment size of 200-500 base pairs. The labelled DNA fragments were purified from remaining nucleotides by column chromatography.

For CGH, 500 ng of tumour DNA, 300 ng of reference DNA, and $30 \mu \mathrm{g}$ of human Cotl DNA (Gibco, Karlsruhe, Germany) were co-precipitated and redissolved in $10 \mu \mathrm{l}$ of hybridisation buffer. Denaturation of DNA $\left(75^{\circ} \mathrm{C}\right.$ for five minutes) was followed by a preannealing time of 45 minutes at $37^{\circ} \mathrm{C}$. Target metaphase spreads $(46, X Y)$, which had been prepared following standard procedures, were denatured separately in $70 \%$ formamide $/ 2 \times \mathrm{SSC}$ for two minutes at $72^{\circ} \mathrm{C}$.

Hybridisation was allowed to proceed for three to four days. Post-hybridisation washes were carried out to a stringency of $50 \%$ formamide $/ 2 \times \mathrm{SSC}\left(\mathrm{NaCl} /\right.$ sodium citrate) at $45^{\circ} \mathrm{C}$ and $0.1 \times \mathrm{SSC}$ at $60^{\circ} \mathrm{C}$. Biotinylated and digoxigenated sequences were detected simultaneously using avidin-FITC (Boehringer Mannheim, 1:200) and anti-digoxigenin-rhodamine (Boehringer Mannheim, 1:40). The slides were counterstained with DAPI and mounted in an antifade solution (Vectashield, Vector Laboratories).

\section{Microscopy and digital image analysis}

Separate digitised grey level images of DAPI, FITC, and rhodamine fluorescence were taken with a CCD camera connected to a Leica DMRBE microscope. The image processing was carried out by use of Applied Imaging software. Average green-red ratios were calculated for each chromosome in at least 10 metaphases.

Chromosomal regions with CGH ratio profiles surpassing the 50\% CGH thresholds (upper threshold 1.25, lower threshold 0.75 ) were defined as loci with copy number gains or losses. For the assignment of these gains to chromosomal bands, the signal intensities were compared to the DAPI banding on individual chromosomes. As tumour specimens and normal DNA were not sex matched, $\mathrm{X}$ and $\mathrm{Y}$ chromosomes were excluded.

\section{RESULTS}

CGH revealed no DNA copy number changes in any of the 29 primary craniopharyngiomas, regardless of their histological subtype. Successful completion and the quality of CGH investigation in each case was established by checking the narrowness of the $95 \%$ confidence interval as well as the loss of the Y and gain of the $\mathrm{X}$ chromosome in tumour material from female patients hybridised on metaphase spreads of a male donor (internal positive control). 


\section{DISCUSSION}

Craniopharyngiomas are benign tumours that show a bimodal age distribution and arise in two distinct clinicopathological variants: the adamantinomatous and the papillary subtypes. ${ }^{1}$ The molecular mechanisms involved in craniopharyngiomas remain elusive. While a genetic susceptibility is not known, there are reports describing the occurrence of craniopharyngiomas in consanguineous siblings ${ }^{2}$ as well as in a mother and daughter. ${ }^{3}$ To date, cytogenetic (that is, karyotypic) data on only 11 craniopharyngiomas have been published, ${ }^{5-8}$ and have shown multiple chromosomal abnormalities in two cases, both of which involved chromosomes 2 and $12,{ }^{57}$ while the other nine cases presented with normal karyotypes ${ }^{6}$; four additional craniopharyngiomas showed no mutations of the TP53 tumour suppressor gene. ${ }^{9}$ In view of the association of naevoid basal cell carcinoma or Gorlin syndrome with the occurrence of craniopharyngiomas, a recent study was carried out on 22 adamantinomatous craniopharyngiomas. This found no mutations in the Gorlin syndrome gene PTCH, localised on chromosome 9q22.3, while the putative protooncogenes encoding the $\alpha$ subunits of the stimulatory (Gs $\alpha$ ) or the inhibitory $($ Gi $2 \alpha)$ GTP binding proteins on respective chromosome subunits 20q13.2 and 3p21 were also found not to be mutated. ${ }^{10}$ Interestingly, a subset of these adamantinomatous craniopharyngiomas turned out to be monoclonal in origin. ${ }^{10}$

While it has to be borne in mind that CGH is only sensitive for detecting deletions that are of the order of several megabases in size, ${ }^{11}$ and that smaller deletions or balanced alterations may thus be missed, the lack of DNA copy number changes in any of our adamantinomatous and papillary craniopharyngiomas is also in accordance with previously published CGH data on low grade cerebral neoplasms: pineocytomas, subependymal giant cell astrocytomas, and pilocytic astrocytomas were reported to show $0,{ }^{4} \quad 0,{ }^{12}$ and $0.3^{13}$ imbalances per tumour, respectively. In view of our data, and most other molecular data on craniopharyngiomas, one has to assume that chromosomal aberrations do not play a major role in their tumorigenesis, and the only two cytogenetically abnormal cases may have represented tissue culture

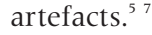

In conclusion, our CGH data suggest that chromosomal imbalances are a rare event in primary adamantinomatous and papillary craniopharyngiomas.

\section{ACKNOWLEDGEMENTS}

The invaluable help and skilful assistance of Ms Beate Schröder is gratefully appreciated.

\section{Authors' affiliations}

C H Rickert, W Paulus, Institute of Neuropathology, University Hospital Münster, Germany

Competing interests: none declared

Correspondence to: Dr Christian H Rickert, University Hospital Münster, Gerhard-Domagk-Institute of Pathology, Domagkstr 17, D-48149

Münster, Germany; rickchr@uni-muenster.de

Received 19 August 2002

Accepted 4 November 2002

\section{REFERENCES}

1 Janzer RC, Burger PC, Giangaspero F, et al. Craniopharyngioma. In: Kleihues $\mathrm{P}, \mathrm{Cavenee}$ WK, eds. Pathology and genetics. Tumours of the nervous system. Lyon: IARC, 2000:244-6.

2 Boch AL, van Effenterre R, Kujas M. Craniopharyngiomas in two consanguineous siblings: case report. Neurosurgery 1997;41:1185-7.

3 Green AL, Yeh JS, Dias PS. Craniopharyngioma in a mother and daughter. Acta Neurochir 2002;144:403-4.

4 Rickert $\mathbf{C H}$, Simon R, Bergmann $M$, et al. Comparative genomic hybridization in pineal parenchymal tumors. Genes Chromosomes Cancer 2001:30:99-104.

5 Gorski GK, McMorrow, Donaldson MH, et al. Multiple chromosomal abnormalities in a case of craniopharyngioma. Cancer Genet Cytogenet 1992;60:212-13

6 Griffin CA, Long PP, Carson BS, et al. Chromosome abnormalities in low-grade central nervous system tumors. Cancer Genet Cytogenet 1992;60:67-73.

7 Karnes PS, Tran TN, Cui MY, et al. Cytogenetic analysis of 39 pediatric central nervous system tumors. Cancer Genet Cytogenet 1992;59:12-19.

8 Vagner-Capodano AM, Gentet JC, Gambarelli D, et al. Cytogenetic studies in 45 pediatric brain tumors. Pediatr Hematol Onco 1992:9:223-35.

9 Nozaki M, Tada M, Matsumoto $R$, et al. Rare occurrence of inactivating p53 gene mutations in primary non-astrocytic tumors of the central nervous system: reappraisal by yeast functional assay. Acta Neuropathol 1998;95:291-6

10 Sarubi JC, Bei H, Adams EF, et al. Clonal composition of human adamantinomatous craniopharyngiomas and somatic mutation analyses of the patched (PTCH), Gs $\alpha$ and Gi2 $\alpha$ genes. Neurosci Lett 2001;310:5-8

11 Bentz M, Plesch A, Stilgenbauer S, et al. Minimal sizes of deletions detected by comparative genomic hybridization. Genes Chromosomes Cancer 1998;21:172-5.

12 Rickert CH, Paulus W. No chromosomal imbalances detected by comparative genomic hybridisation in subependymal giant cell astrocytomas. Acta Neuropathol 2002;104:206-8.

13 Sanoudou D, Tingby O, Ferguson-Smith MA, et al. Analysis of pilocytic astrocytoma by comparative genomic hybridization. $\mathrm{Br} J$ Cancer 2000;82:1218-22. 